\title{
Prolonged Physiotherapy versus Early Surgical Intervention in Patients with Lumbar Disk Herniation: Short-term Outcomes of Clinical Randomized Trial
}

\author{
Doaa Abdelmohsen Abou-Elroos ${ }^{1,2}$, Mirvat Abd El-Hameed El-Toukhy ${ }^{2}$, \\ Ghada Sanad Nageeb², Essam Abdelhameed Dawood ${ }^{3}$, Safwat Abouhashem ${ }^{3,4}$ \\ ${ }^{1}$ Department of Rheumatology and Rehabilitation, Kenayat Hospital, Kenayat city, Egypt \\ ${ }^{2}$ Department of Rheumatology and Rehabilitation, Faculty of Medicine, Zagazig University, Sharkia, Egypt \\ ${ }^{3}$ Department of Neurosurgery, Faculty of Medicine, Zagazig University, Sharkia, Egypt \\ ${ }^{4}$ Neurosurgery Division, Kingdom Hospital, Riyadh, Saudi Arabia
}

\begin{abstract}
Study Design: Randomized controlled trial.
Purpose: We compared the disability and functional outcome after conservative treatment with prolonged physiotherapy versus early surgical intervention in patients with lumbar disk herniation.

Overview of Literature: Lumbar disk herniation is one of the most common causes of job-related disability in individuals less than 45 years old. Conservative treatment is the initial pathway for the majority of patients but the duration of conservative treatment remains debatable and the adverse effects of prolonged conservative treatment are still unclear. Prolonged duration of symptoms before surgical intervention is associated with worse outcomes than a short period of symptoms.

Methods: From June 2011 to July 2013, 60 patients with lumbar disk herniation at our institute were randomized into two groups. Group I was treated with prolonged physiotherapy and rehabilitation for 6 months, while group || was treated with early surgical discectomy. Oswestry disability index was used to assess disability, while the Prolo economic outcome rating scale was used to assess the work status.

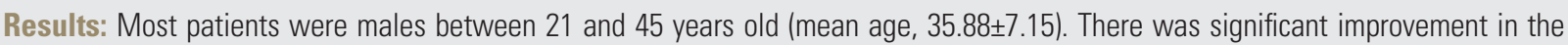
disability and work status in both groups without statistically significant differences in the disability score at the second or third assessment. However, the Prolo scale became significantly better in group I than in group II patients during the second and third assessments. Conclusions: A prolonged physiotherapy and rehabilitation program is a beneficial and successful treatment in patients with recently diagnosed lumbar disk herniation.
\end{abstract}

Keywords: Disk herniation; Physiotherapy; Discectomy; Disability

\section{Introduction}

Intervertebral disk degeneration is considered the most common cause of low back pain and job-related disability in individuals less than 45 years old [1,2]. It is an aging process [3] with multiple hereditary, genetic, environmen-

Received Nov 27, 2016; Revised Dec 19, 2016; Accepted Jan 10, 2017

Corresponding author: Safwat Abouhashem

Department of Neurosurgery, Faculty of Medicine, Zagazig University, Sharkia, Egypt

Tel: +966559142014, Fax: 0096611275234, E-mail: sabohashem@gmail.com 
tal, and socioeconomic factors contributing to poor disk health, with subsequent degeneration and herniation $[4,5]$. There is a wide variety of symptoms and signs related to lumbar disk herniation, but the main clinical manifestations are back pain and radicular symptoms in the form of sciatic pain, sensory loss, or even motor weakness, and rarely autonomic manifestations $[2,6,7]$.

Conservative treatment usually is the initial pathway for the majority of cases of lumbar disk herniation with a favorable outcome [1], while early surgery is limited to certain conditions, such as progressive neurologic deficit or if the patient presented with cauda equina $[1,8]$. Physiotherapy and spinal manipulation during the acute stage of lumbar disk herniation did not show strong evidence to support its use in the acute stage and controversy over its use remains [9]. The duration of conservative treatment for lumbar disk herniation remains debatable and the adverse effects of prolonged conservative treatment still are unclear $[8,10,11]$. In addition, prolonged symptoms of lumbar disk herniation are associated with worse surgical outcomes than is a short period of symptoms before surgical intervention [7].

Despite multiple studies in the medical literature comparing surgical and conservative treatment, there are limited evidence-based conclusions regarding the optimal treatment for lumbar disk herniation [11-15]. Multiple prognostic factors exist, involving not only the radiologic findings but also the time of intervention, age, sex, smoking, obesity, and socioeconomic factors, that can affect the outcome of management $[7,10,16,17]$.

The aim of this study was to compare the outcome of conservative treatment and prolonged physiotherapy versus early surgical intervention in patients with recentonset lumbar disk herniation.

\section{Materials and Methods}

Of all patients who presented to the Departments of Rheumatology and Neurosurgery at Zagazig University Hospitals between June 2011 and July 2013, 127 with recent-onset low back pain and sciatica due to lumbar disk herniation, whose diagnosis was confirmed by magnetic resonance imaging (MRI) and who fulfilled the inclusion and exclusion criteria of this study, were asked to be included in the study (Fig. 1). All patients between 18 and 45 years of age with single- or double-level disk herniation and symptoms less than 3 months in duration were included. Patients with a history of lumbar surgery, pro-

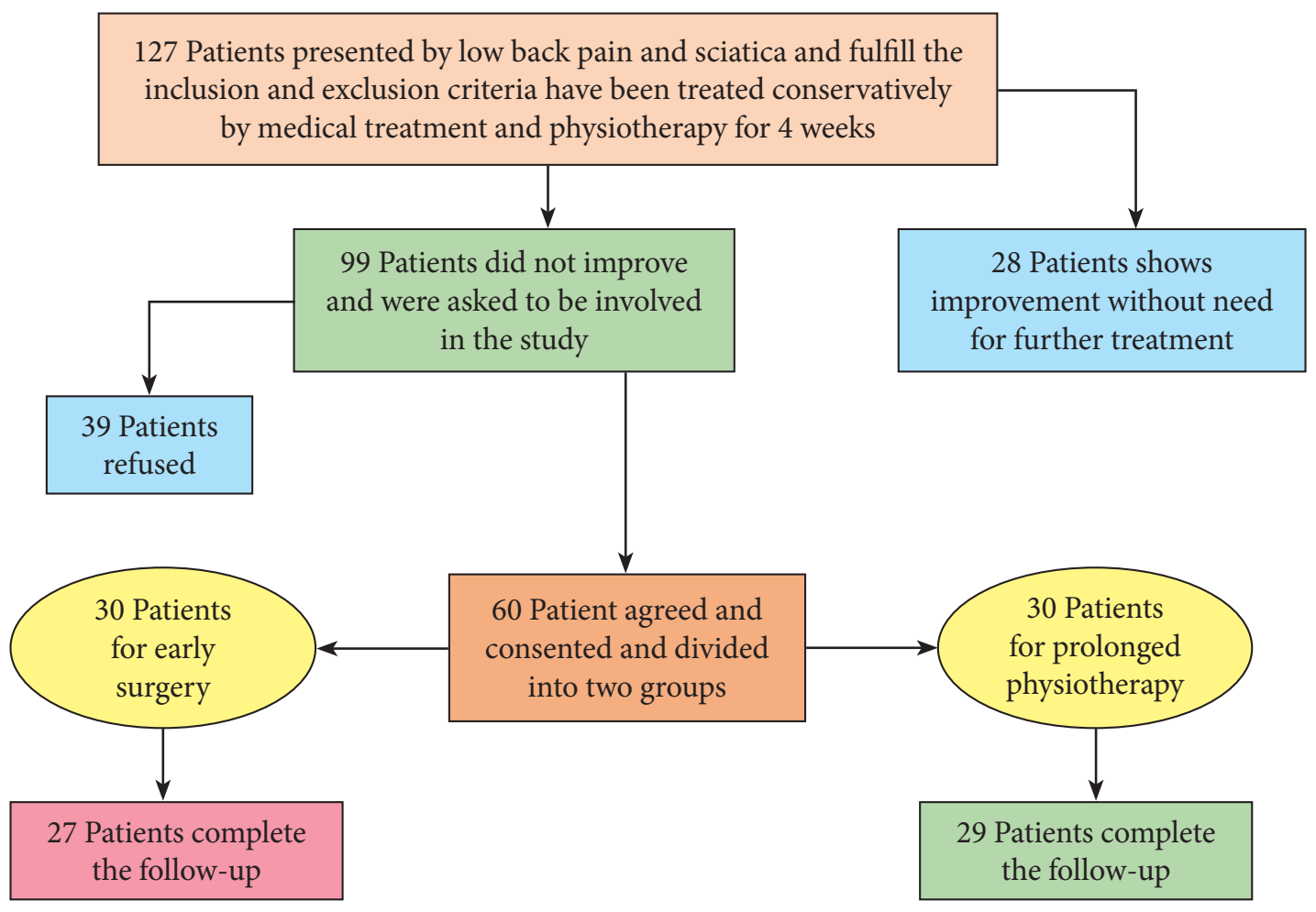

Fig. 1. Enrollment and randomization of the patients. 
gressive neurologic deficit, initial presentation with cauda equina, lumbar canal stenosis, spondylolisthesis, or systemic diseases that interfered with the exercise protocol or increased the risk of surgical complication were excluded.

All patients were treated initially by conservative measures for 4 weeks in the form of activity modification; soft tissue massage; electrotherapy; static exercises for abdominal muscles, back muscles, and hip extensors; stretching exercises to the hamstring as well as range of motion (ROM) exercises; and medical treatment using muscle relaxants, analgesics, antiinflamatory medication, pregabalin, and vitamen B complex. After 4 weeks, 99 patients did not show satisfactory improvement. The 60 patients who agreed to be involved in the study provided consent, and were randomized into two groups except for four who were lost during follow-up (Fig. 1). Group I consisted of 29 patients with lumbar disk herniation treated medically and by a prolonged physiotherapy program for 6 months. Group II consisted of 27 patients with lumbar disk herniation treated by early discectomy after the failure of 4 weeks of conservative treatment.

The patient disability, functional status, and ability to work were assessed at the beginning of the study, and after 3 and 6 months. The Oswestry disability index (ODI) [18] was used for disability assessment, while the work status was evaluated using the Prolo economic outcome rating scale [19].

The data were computerized and analyzed statistically using SPSS ver. 11 (SPSS Inc., Chicago, IL, USA). Quantitative data were represented as range, arithmetic means, and standard deviations $( \pm \mathrm{SD})$ and a paired $t$ test was used for comparison of the means between the two groups. Correlation was carried out to compare different parameters, while qualitative data were represented as fre- quencies and percentages. The chi-square and McNemar tests were performed to calculate significant differences between the qualitative data in both groups whenever possible. Otherwise, Fisher exact test was conducted when the expected cell was $<5$. The result was considered statistically significant when the significant probability was less than $5 \%(p<0.05)$.

\section{Results}

A total of 56 patients with recent-onset symptomatic lumbar disk herniation completed the follow-up. Patients' age ranged between 21 and 45 years (mean age, $35.88 \pm 7.15$ years).There were 45 (80.4\%) male and 11 female (19.6\%) patients. The duration of the complaint was $65 \pm 25$ days in group I and $70 \pm 20$ days in group II (Table 1).

All patients presented with low back pain and/or sciatica. The duration of symptoms was not more than 3 months and the diagnosis was confirmed by MRI. All patients were treated initially by conservative measures for 4 weeks, including activity modification; soft tissue massage; electrotherapy; static exercises for abdominal muscles, back muscles, and hip extensors; stretching exercises to the hamstring; as well as ROM exercises and medical treatment.

The observed risk factors were obesity, smoking, and heavy work, while diabetes was detected in only 8 patients (14.2\%). There was no significant difference between the groups regarding age, sex, body weight, smoking, diabetes, and nature of work ( $p=0.13, p=0.84, p=0.89, p=0.37$, $p=0.91$, and $p=0.51$, respectively) (Table 1 ).

In the present study, 44 herniated disks were diagnosed in group I and 39 in group II, but there was no significant difference between both groups regarding the number,

Table 1. Patients criteria

\begin{tabular}{lccc}
\hline Patients criteria & Group I $(\mathrm{n}=29)$ & Group II $(\mathrm{n}=27)$ & p-value \\
\hline Duration of the symptoms & $65 \pm 25$ & $70 \pm 20$ & 0.56 \\
\hline Age $(\mathrm{yr})$ & $34.48 \pm 7$ & $37.37 \pm 7$ & 0.13 \\
\hline Male/female & $23(79.3) / 6(20.7)$ & & 0.84 \\
\hline Risk factors & & $28.5 \pm(8) / 5(18.5)$ & 0.99 \\
\hline Body mass index & $28.4 \pm 3.6$ & $144 \pm 50.6$ & 0.37 \\
\hline Smoking index & $138 \pm 49.4$ & $4(14.8)$ & 0.91 \\
\hline Diabetic patients & $4(13.8)$ & $14(51.6)$ & 0.51 \\
\hline Heavy workers & $14(48.3)$ & & \\
\hline
\end{tabular}

Values are presented as mean \pm standard deviation or number (\%). 
Table 2. Radiological findings

\begin{tabular}{lccc}
\hline Radiological findings & Group I $(\mathrm{n}=29)$ & Group II (n=27) & $p$-value \\
\hline No. of hernited discs & 44 & $2(5.1)$ & 0.28 \\
\hline L3-4 & $4(9.1)$ & $19(48.7)$ & 0.44 \\
\hline L4-5 & $17(38.6)$ & $18(46.2)$ & 0.19 \\
\hline L5-S1 & $23(52.3)$ & $15(52.6)$ & 0.17 \\
\hline Single level & $14(48.4)$ & $12(44.8)$ & 0.14 \\
\hline Double level & $15(51.6)$ & & 0.09 \\
\hline Grade of herniation & & $24(61.5)$ & 0.35 \\
\hline Disc protrusion & $29(65.9)$ & $11(28.2)$ & 0.45 \\
\hline Disc extrusion & $13(29.5)$ & $4(10.3)$ & 0.14 \\
\hline Disc sequestration & $2(4.6)$ & & \\
\hline
\end{tabular}

Values are presented as number (\%).

Table 3. Disability and functional status

\begin{tabular}{lccc} 
Disability & Group I (n=29) & Group II (n=27) & $p$-value \\
Oswestry disability index & $60.66 \pm 9.7$ & $62.2 \pm 15.8$ & 0.09 \\
Moderate disability & $3(10.3)$ & $1(3.7)$ & 0.17 \\
\hline Sever disability & $17(58.6)$ & $16(59.3)$ & 0.19 \\
Crippled & $9(31)$ & $10(37)$ & 0.09 \\
Prolo scale & $2.13 \pm 0.7$ & $2.03 \pm 0.9$ & 0.69 \\
\hline
\end{tabular}

Values are presented as mean \pm standard deviation or number (\%).

Table 4. Oswestry disability index in both groups during first, second and third assessment

\begin{tabular}{lccc} 
Oswestry disability score & Group I $(\mathrm{n}=29)$ & Group II $(\mathrm{n}=27)$ & $p$-value \\
First assessment & $60.66 \pm 9.7$ & $62.2 \pm 15.8$ & 0.09 \\
Second assessment & $30.62 \pm 17.54$ & $37.48 \pm 18.05$ & 0.06 \\
Third assessment & $29.1 \pm 15.4$ & $32.9 \pm 15.5$ & 0.3 \\
\hline
\end{tabular}

Values are presented as mean \pm standard deviation.

Table 5. Prolo economic outcome rating scale of both groups at first, second and third assessments

\begin{tabular}{lcrc} 
Outcome & Group I $(\mathrm{n}=29)$ & Group II $(\mathrm{n}=27)$ & $p$-value \\
First assessment & $2.13 \pm 0.7$ & $2.03 \pm 0.9$ & 0.69 \\
Second assessment & $3.93 \pm 0.7^{\mathrm{a})}$ & $3.1 \pm 1.1$ & 0.03 \\
\hline Third assessment & $4.4 \pm 0.3^{\mathrm{a})}$ & $3.9 \pm 0.4$ & 0.05 \\
\hline
\end{tabular}

Values are presented as mean \pm standard deviation.

${ }^{\text {a) }}$ Statistically significant difference.

level, or grade of herniated disks (Table 2).

Most patients in both groups showed progressive improvement during the study. At first assessment, the mean ODI was $60.66 \pm 9.7$ in group I and $62.2 \pm 15.8$ in group II. After 3 months, the ODI scores were $30.62 \pm 17.54$ and $37.48 \pm 18.05$, respectively. After 6 months at the end of the study, the ODI scores were $29.1 \pm 15.4$ and $32.9 \pm 15.5$, respectively (Tables 3,4 ).

During the first assessment, the mean Prolo scale score was $2.13 \pm 0.7$ and $2.03 \pm 0.9$ in groups I and II, respectively. The Prolo scale scores were $3.93 \pm 0.7$ and $3.1 \pm 1.1$, respectively, after 3 months, and $4.4 \pm 0.3$ and $3.9 \pm 0.4$, respectively, after 6 months (Tables 3, 5). At the endpoint of the study, $62 \%$ of the patients in group I returned to their 
initial job compared to only $41 \%$ in group II (Fig. 2).

\section{Discussion}

Despite conservative treatment for lumbar disk herniation, the initial pathway for treatment and early surgery is limited due to the progressive neurologic deficit or cauda equina $[1,8]$. In addition, prolonged duration of symptomatic lumbar disk herniation is usually associated with worse outcomes than is a short period of symptoms before surgical intervention [7]. Multiple studies [9,11$15,20-22]$ in the medical literature have compared surgical and conservative treatment of patients with lumbar disk herniation, but there are limited evidence-based conclusions regarding optimal treatment, duration of conservative treatment, and the benefits of early physiotherapy. The contradictions between studies in the outcome after management of lumbar disk herniation can be attributed to the multiplicity of prognostic factors and different outcome measures.

We believe that functional ability and returning to work are important indicators for the success of management. Therefore, in the current study, we compared the functional disability outcome and ability to work in patients who were diagnosed recently with symptomatic lumbar disk herniation.

The degree of success after certain treatments may be influenced by patient selection, different outcomes variables, follow-up time, and magnitude and duration of mechanical compression of the disk fragment on the nerve roots, in addition to the presence of risk factors that may

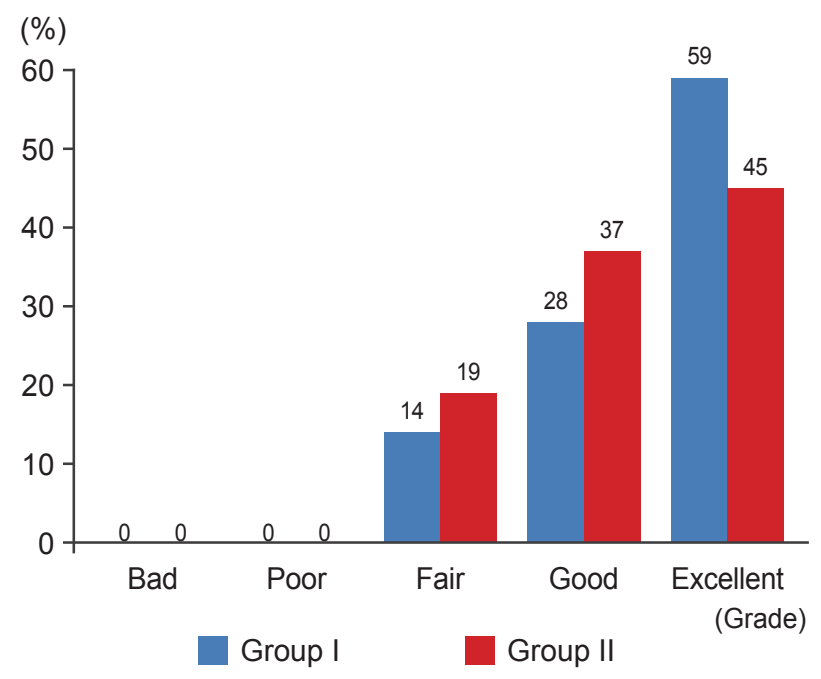

Fig. 2. Prolo economic outcome rating scale. have an adverse effect [12-15,22]. Epidemiologic factors, radiologic and clinical findings, in addition to socioeconomic factors, may affect not only the symptoms and signs but the outcomes of management $[7,12,16,17,20,21]$. These factors were not evaluated in this study as there was no statistically significant difference between patients in both groups regarding all of them.

In this study, evaluation of the disability score (ODI) [18] after 3 and 6 months showed significant improvement in both groups during the second or third assessment versus the first assessment. However, when we compared the third versus the second assessments, there was no statistically significant difference. Evaluation of the work status using the Prolo outcome economic rating scale [19] showed statistically significant improvement in both groups when the second or third assessment was compared to the first assessment. However, the mean Prolo scale score was significantly better in group I than in group II patients during the second $(p=0.03)$ and third $(p=0.05)$ assessments.

Although improvement of patients with lumbar disk herniation after surgical or conservative treatment has been reported in multiple previous studies [11-14,20,21], there were different degrees of improvement and contradictions between the superiority of surgical intervention and conservative treatment.

The results of the current study are quite similar to those of Atlas et al. [12], who found that the disability is similar in patients with lumbar disk herniation after treatment at 4, 5, and 10 years of follow-up regardless of the treatment. However, they found a relative advantage of operative treatment regarding leg pain and patient satisfaction. This relative advantage of surgery over conservative treatment usually decreased with time and a narrowing of the difference occurred during the first 2 to 4 years. They also found no difference between the patients who were treated conservatively or surgically in the ability to work (19\% of surgically treated patients and $17 \%$ of nonsurgically treated patients were receiving compensation at the beginning of the study, while at 10 years, $5 \%$ of the patients were receiving compensation regardless of the treatment).

Older studies have reported better results with surgical treatment than with conservative treatment. Moderate improvement was detected in only $38 \%$ of patients randomized to conservative treatment and $20 \%$ of them required subsequent laminectomy [21]. Other studies reported that patients with lumbar disk prolapse who were treated 
surgically had better physical function and work ability than those who were treated conservatively after 3 months $[13,14]$; however, this difference was decreasing at 2 years of follow-up [15]. Hahne et al. [20] also reported results different from those of our current study, as conservative treatment was less effective than surgical treatment at short-term follow-up and was of no significant difference at long-term follow-up.

The disability of patients in the current study is in contrast with the findings in the Spine Patient Outcomes Research Trial (SPORT) $[13,14]$ at 3 months of followup, since despite the presence of significant improvement in surgical and nonsurgical treatment, those patients who selected surgical treatment had better functional recovery than those who selected nonsurgical treatment. The mean change in the ODI was 37.6 in the surgical group and 24.2 in the nonsurgical group [13,14], but patients in both arms of the SPORT [13-15], which compared surgical versus nonsurgical treatment for patients with lumbar disk herniation, improved substantially over the first 2 years. The superiority of surgical intervention was not statistically significant except for sciatica severity and self-rated improvement [15]. The superiority of the surgical over nonsurgical treatments in the SPORT [13-15] was potentially confounding and should be interpreted cautiously due to the nonadherence of the patients to the assigned treatment [15], as it was found that patients who crossed over to surgery had lower incomes, worse symptoms, and more disability, and usually were exaggerating their symptoms to be worse during follow-up than at enrollment, while patients who crossed over to receive conservative treatment were older, had higher incomes and tolerable symptoms with better function and less disability $[13,14]$.

We believe that the difference in the work ability outcome between patients in the current study and other studies may be due to different polices of retirement and work compensation between developing and developed countries. It also may be due to the nature or work of our patients, as most of them were heavy workers

\section{Conclusions}

A prolonged physiotherapy and rehabilitation program is a beneficial modality in patients with recently diagnosed lumbar disk herniation. Such a program may improve the functional capacity and facilitate return to work more than early surgical intervention.

\section{Conflict of Interest}

No potential conflict of interest relevant to this article was reported.

\section{References}

1. Gregory DS, Seto CK, Wortley GC, Shugart CM. Acute lumbar disk pain: navigating evaluation and treatment choices. Am Fam Physician 2008;78:83542.

2. Taher F, Essig D, Lebl DR, et al. Lumbar degenerative disc disease: current and future concepts of diagnosis and management. Adv Orthop 2012;2012:970752.

3. Benoist M. Natural history of the aging spine. Eur Spine J 2003;12 Suppl 2:S86-9.

4. Katz JN. Lumbar disc disorders and low-back pain: socioeconomic factors and consequences. J Bone Joint Surg Am 2006;88 Suppl 2:21-4.

5. Samartzis D, Karppinen J, Chan D, Luk KD, Cheung $\mathrm{KM}$. The association of lumbar intervertebral disc degeneration on magnetic resonance imaging with body mass index in overweight and obese adults: a population-based study. Arthritis Rheum 2012; 64:1488-96.

6. Ahn UM, Ahn NU, Buchowski JM, Garrett ES, Sieber AN, Kostuik JP. Cauda equina syndrome secondary to lumbar disc herniation: a meta-analysis of surgical outcomes. Spine (Phila Pa 1976) 2000;25:1515-22.

7. Rahme R, Moussa R, Bou-Nassif R, et al. Lumbar microdiscectomy: a clinicoradiological analysis of outcome. Can J Neurol Sci 2011;38:439-45.

8. Taha MM, Abouhashem S. Spontaneous resorption of extruded lumbar disk herniation: report of five cases. J Spine Neurosurg 2015;4:3.

9. Snelling NJ. Spinal manipulation in patients with disk herniation: a critical review of risk and benefit. Int J Osteopath Med 2006;9:77-84.

10. Sutheerayongprasert C, Paiboonsirijit S, Kuansongtham V, Anuraklekha S, Hiranyasthiti N, Neti S. Factors predicting failure of conservative treatment in lumbar-disk herniation. J Med Assoc Thai 2012;95: 674-80.

11. Weinstein JN, Lurie JD, Tosteson TD, et al. Surgical vs nonoperative treatment for lumbar disk herniation: the Spine Patient Outcomes Research Trial (SPORT) observational cohort. JAMA 2006;296:2451-9. 
12. Atlas SJ, Keller RB, Wu YA, Deyo RA, Singer DE. Long-term outcomes of surgical and nonsurgical management of sciatica secondary to a lumbar disc herniation: 10 year results from the maine lumbar spine study. Spine (Phila Pa 1976) 2005;30:927-35.

13. Atlas SJ, Keller RB, Chang Y, Deyo RA, Singer DE. Surgical and nonsurgical management of sciatica secondary to a lumbar disc herniation: five-year outcomes from the Maine Lumbar Spine Study. Spine (Phila Pa 1976) 2001;26:1179-87.

14. Weinstein JN, Tosteson TD, Lurie JD, et al. Surgical vs nonoperative treatment for lumbar disk herniation: the Spine Patient Outcomes Research Trial (SPORT): a randomized trial. JAMA 2006;296:244150.

15. Weinstein JN, Lurie JD, Tosteson TD, et al. Surgical versus nonoperative treatment for lumbar disc herniation: four-year results for the Spine Patient Outcomes Research Trial (SPORT). Spine (Phila Pa 1976) 2008;33:2789-800.

16. Abouhashem S, Taha MM. Impact of obesity on the functional recovery after lumbar discectomy. Internet J Neurosurg 2015;12. https://doi.org/10.5580/
IJNS.35980.

17. Silverplats K, Lind B, Zoega B, et al. Clinical factors of importance for outcome after lumbar disc herniation surgery: long-term follow-up. Eur Spine J 2010; 19:1459-67.

18. Fairbank JC, Couper J, Davies JB, O’Brien JP. The Oswestry low back pain disability questionnaire. Physiotherapy 1980;66:271-3.

19. Prolo DJ, Oklund SA, Butcher M. Toward uniformity in evaluating results of lumbar spine operations: a paradigm applied to posterior lumbar interbody fusions. Spine (Phila Pa 1976) 1986;11:601-6.

20. Hahne AJ, Ford JJ, McMeeken JM. Conservative management of lumbar disc herniation with associated radiculopathy: a systematic review. Spine (Phila Pa 1976) 2010;35:E488-504.

21. Gogan WJ, Fraser RD. Chymopapain: a 10-year, double-blind study. Spine (Phila Pa 1976) 1992;17:38894.

22. Carragee EJ, Han MY, Suen PW, Kim D. Clinical outcomes after lumbar discectomy for sciatica: the effects of fragment type and anular competence. J Bone Joint Surg Am 2003;85:102-8. 